\title{
Diagnóstico do Funcionamento do Conselho de Classe no IFMT-Campus Cuiabá Cel. Octayde Jorge da Silva
}

\section{Diagnosis of the Functioning of the Class Council atIFMT-Campus Cuiabá Cel. Octayde Jorge da Silva}

\author{
Elisandra Regina Muxfeldta; Albéria Cavalcanti de Albuquerque*a
}

anstituto Federal de Mato Grosso, Programa de Pós-Graduação Stricto Sensu em Educação Profissional e Tecnológica. MT, Brasil.

*E-mail: elisandra.muxfeldt@cba.ifmt.edu.br

\begin{abstract}
Resumo
Este trabalho foi motivado pela expectativa de diagnosticar, a partir dos documentos vigentes, a atual forma de organização e de funcionamento do Conselho de Classe no IFMT- campus Cuiabá Cel. Octayde Jorge da Silva. Foi usada uma abordagem qualitativa com característica exploratória, por meio da Técnica da Documentação Indireta: pesquisa bibliográfica e pesquisa documental. Para tanto, buscou-se um embasamento teórico por meio de bibliografias referentes ao Conselho de Classe e em documentos legais como: a LDB/96; o Projeto Pedagógico Institucional do IFMT/2019 e a Organização Didática do IFMT/2014. Com base nos documentos legais se concluiu que o Conselho de Classe deve ser instituído nas escolas de forma participativa e colegiada, e que essa instância possui uma função importante no tocante ao acompanhamento do processo de ensino e aprendizagem. Todavia, não foram encontrados, no âmbito da Instituição, documentos com orientações para a prática da organização e do funcionamento do Conselho de Classe. Assim, identificou-se a necessidade de se construírem tais instrumentos, com vistas a ações mais efetivas para a execução, o acompanhamento e a avaliação do processo pedagógico nos cursos Técnicos Integrados ao Ensino Médio.
\end{abstract}

Palavras-chave: Projeto Pedagógico Institucional. Organização Didática. Ensino-Aprendizagem. Avaliação Escolar. Ensino Médio Integrado.

\begin{abstract}
This work was motivated by the expectation of diagnosing, based on the current documents, the current form of organization and functioning of the Class Council at the IFMT-campus Cuiabá Cel. Octayde Jorge da Silva. A qualitative approach with an exploratory characteristic was used, through the Indirect Documentation Technique: bibliographic research and documentary research. To this end, a theoretical basis was sought through bibliographies regarding the Class Council and in legal documents such as: LDB / 96; the Institutional Pedagogical Project of IFMT / 2019 and the Didactic Organization of IFMT / 2014. Based on the legal documents, it was concluded that the Class Council should be instituted in schools in a participatory and collegial way, and that this instance has an important role regarding the teaching-learning process monitoring. However, no documents were found, within the institution, with guidelines for the organization practice and the Class Council functioning. Thus, the need to build such instruments was identified, with a view to more effective actions for the execution, monitoring and evaluation of the pedagogical process in the Technical courses integrated to High School.
\end{abstract}

Keywords: Institutional Pedagogical Project. Didactic Organization. Teaching-Learning. School Evaluation. Integrated High School.

\section{Introdução}

O Conselho de Classe é uma das instâncias formalmente instituídas, no ambiente escolar, e tem como objetivo central a avaliação do processo de ensino e aprendizagem. Apresentase com características especiais em relação a outras instâncias colegiadas, por guardar em si a possibilidade de articular os diversos segmentos da escola (DALBEN, 1992).

Considera-se a escola como uma organização social com função de agente transformador, com responsabilidades na formação humana, por meio de práticas sociais, políticas e pedagógicas (DOURADO, 2012). Participar desse processo instiga a refletir sobre a atuação de todos os envolvidos, observando a realidade em que se está inserido, identificando ações já condicionadas e perspectivas de melhoria das condições de atuação no processo educativo. Compreende- se ser de grande importância não só lançar um olhar para a prática adotada nos Conselhos de Classe, como também repensar como e de que forma este espaço poderá contribuir para o processo de ensino e aprendizagem.

Percebe-se, em um contexto histórico, que a prática dos Conselhos de Classe, em muitas escolas, está aliada a uma verificação do desempenho do estudante, em que são normalmente observados o baixo rendimento ou os problemas comportamentais, dessa forma atestando o fracasso escolar dos estudantes (PIZOLI, 2009). Ter o Conselho de Classe como objeto de pesquisa foi um desafio estabelecido pelas autoras, por se tratar de um tema pouco estudado e discutido nos ambientes escolares.

Como forma de contextualizar a expectativa quanto ao assunto investigado, considera-se importante estreitar os passos que se fizeram até aqui. Inicialmente, pode-se 
considerar que a motivação pelo tema surgiu das experiências vivenciadas pelas autoras, como Técnica em Assuntos Educacionais e como docente, nas reuniões de Conselho de Classe dos cursos de Ensino Médio Integrado ao Ensino Técnico do Instituto Federal de Mato Grosso - IFMT, Campus Cuiabá - Cel. Octayde Jorge da Silva.

Como membros participantes nos Conselhos de Classe no referido campus e em decorrência da vivência profissional, alguns questionamentos surgiram: o que se tem feito para, efetivamente, se tornar um conselho com função diagnóstica? Sua prática contribui de alguma forma para a reflexão do processo de ensino e aprendizagem? No atual formato, há condições de um acompanhamento eficaz? Como sua prática pode auxiliar e contribuir para uma melhor organização do trabalho pedagógico escolar? O que pode ser feito para uma melhor comunicação entre professores, coordenadores e equipe pedagógica, com a finalidade de auxiliar no processo de ensino e aprendizagem? Há algum documento norteador para a prática do Conselho de Classe no campus?

Partindo dos questionamentos, compreendeu-se ser de grande importância não só lançar um olhar para a prática adotada nos Conselhos de Classe, como também repensar como e de que forma este espaço pode contribuir para o processo de ensino e aprendizagem.

Sendo assim, o presente estudo se balizou pela necessidade de identificar a proposta pedagógica da instituição em relação ao Conselho de Classe, ancorada na análise da LDB/96 (BRASIL, 1996), do Projeto Pedagógico Institucional - PPI (IFMT, 2019) e da Organização Didática (IFMT, 2014).

\section{Desenvolvimento}

\subsection{Metodologia}

Para a consolidação dos objetivos desta pesquisa se optou por uma abordagem qualitativa, de caráter exploratório, considerando-se como a forma mais adequada para compreender o fenômeno investigado. Para Minayo (2002, p.21), a pesquisa qualitativa "[...] trabalha com um universo de motivos, aspirações, crenças, valores e atitudes, o que corresponde a um espaço mais profundo das relações [...]", se preocupando com questões que não podem ser quantificadas.

Como forma metodológica foi utilizada a técnica da documentação indireta: pesquisa bibliográfica e pesquisa documental, pautada em Marconi e Lakatos (2017). No Quadro 1 está apresentado o desenho da pesquisa.

$\mathrm{Na}$ pesquisa bibliográfica foram buscados elementos teóricos para fundamentar as reflexões que envolvem o processo educacional, especialmente, no que tange à Educação Profissional Técnica de Nível Médio e à gestão escolar, com o intuito de compreender a importância da efetiva prática do Conselho de Classe no processo pedagógico.

Posteriormente, a pesquisa documental se debruçou sobre as legislações e atos normativos institucionais do IFMT e do campus em estudo, a fim de identificar subsídios para o desenvolvimento da prática do Conselho de Classe nesta instituição. As constatações encontradas, bem como as respectivas discussões e análises, são apresentadas a seguir.

Quadro 1 - Desenho de Pesquisa

\begin{tabular}{|c|l|}
\hline Título & $\begin{array}{l}\text { Conselho de Classe - IFMT Campus Cuiabá } \\
\text { Cel. Octayde Jorge da Silva }\end{array}$ \\
\hline $\begin{array}{c}\text { Problema } \\
\text { da Pesquisa }\end{array}$ & $\begin{array}{l}\text { Necessidade de Identificar a proposta } \\
\text { pedagógica da instituição em relação ao } \\
\text { Conselho de Classe. }\end{array}$ \\
\hline $\begin{array}{c}\text { Objetivo } \\
\text { Geral }\end{array}$ & $\begin{array}{l}\text { Descrever e refletir sobre os elementos } \\
\text { constitutivos para a organização } \\
\text { e funcionamento dos Conselhos de Classe }\end{array}$ \\
\hline $\begin{array}{c}\text { Objetivos } \\
\text { Específicos }\end{array}$ & $\begin{array}{l}\text { Realizar uma pesquisa documental das bases } \\
\text { legais relativas ao Conselho de Classe; } \\
\text { Realizar uma pesquisa documental relativa ao } \\
\text { Conselho de Classe no IFMT; } \\
\text { Correlacionar as bases legais com as } \\
\text { normativas existentes no IFMT. }\end{array}$ \\
\hline $\begin{array}{c}\text { Tipo de } \\
\text { Pesquisa }\end{array}$ & $\begin{array}{l}\text { Abordagem qualitativa com caráter } \\
\text { exploratório. }\end{array}$ \\
\hline Técnica & $\begin{array}{l}\text { Técnica da Documentação Indireta por meio de } \\
\text { pesquisa documental e pesquisa bibliográfica. }\end{array}$ \\
\hline $\begin{array}{c}\text { Resultado } \\
\text { esperado }\end{array}$ & $\begin{array}{l}\text { Diagnóstico da atual forma de organização e } \\
\text { funcionamento do conselho de classe no IFMT } \\
\text { Campus Cuiabá Cel. Octayde Jorge da Silva }\end{array}$ \\
\hline
\end{tabular}

\subsection{Ensino Médio integrado à Educação Profissional - da legislação à prática}

Conforme a Lei de Diretrizes e Bases da Educação, a Educação Profissional Técnica de Nível Médio - EPTNM, será desenvolvida de forma subsequente, para os estudantes que já tenham concluído o Ensino Médio ou de forma articulada com esse nível de ensino, tendo como finalidade a preparação para o exercício das profissões técnicas (BRASIL, 2008). A referida lei estabelece também que a educação compreende os processos formativos, que se desenvolvem em vários aspectos da convivência, tanto familiar e social, quanto nas organizações da sociedade civil e em manifestações culturais, como nas Instituições de Ensino (BRASIL, 1996).

O Ensino Médio Integrado à Educação Profissional é ofertado pela Rede Federal de Educação, sendo instituído

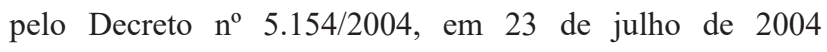
(BRASIL, 2004), que revogou o Decreto de $n^{\circ}$ 2.208/97, o qual determinava a separação do Ensino Médio e da Educação Profissional. Com o Decreto 5.154/2004 se instituiu novamente a articulação entre a Educação Básica e a Educação Profissional, abrangendo dessa forma a oferta na forma integrada ou concomitante, buscando assim uma concepção de formação unitária, a fim de romper com a dualidade estrutural que, historicamente, separou o ensino propedêutico e a formação profissional no Brasil.

A Lei de criação dos Institutos Federais, em seu Art. $7^{\circ}$, seção III, bem define os objetivos dos Institutos Federais: a educação profissional técnica de nível médio deverá, prioritariamente, ser na forma de cursos integrados, para os concluintes do Ensino Fundamental e para o público 
da Educação de Jovens e Adultos; e complementa que os processos educativos devem ser estimulados e apoiados com vistas geração de trabalho e renda e a emancipação do cidadão (BRASIL, 2008).

Nesse contexto, o Ensino Médio Integrado à Educação Profissional não pode ser entendido meramente na concepção da união das disciplinas básicas com as da área profissional, mas, sim, na perspectiva de uma formação integral, completa, sendo que essa integração, para Ramos (2007, p.16), deve possibilitar uma: “[...] formação omnilateral dos sujeitos, pois implica a integração das dimensões fundamentais da vida que estruturam a prática social. Essas dimensões são o trabalho, a ciência e a cultura."

Para Araujo e Frigotto (2015), o Ensino Médio Integrado condiz com uma proposta para a promoção da autonomia dos sujeitos e está em oposição à fragmentação do ensino. Além disso, vem imbuído da ideia de uma prática pedagógica orientadora, no sentido de desenvolver nos jovens e adultos uma capacidade de compreensão mais ampla de sua realidade, promovendo a autonomia do estudante e uma visão mais ampla de Mundo.

Portanto, para que se efetive um ensino integrado que contemple a formação integral do indivíduo, muitas reflexões e desafios deverão estar presentes no contexto educacional.

Em síntese, a implementação do Ensino Médio Integrado dentro de uma instituição não se resume a questões didáticopedagógicas, ou ao projeto curricular de ensino. Requer a superação de diversos desafios dentre eles os de gestão; pedagógicos; condições de ensino; condições materiais; hábitos estabelecidos culturalmente que limitam a formação integrada do aluno (COSTA, 2012, p. 38).

Para um efetivo avanço na construção de um Ensino Médio Integrado na Rede Federal, se faz necessário um compromisso coletivo com vistas a perspectivas de transformação. Para tanto, considerar-se-á, primeiramente, a necessidade de compreender esta complexa implementação e, por conseguinte, promover permanentemente formação continuada para os profissionais da educação. Além disso, faz-se necessário, também: assumir uma cultura democrática; garantir espaços de participação, tanto dos profissionais de educação como dos membros da comunidade escolar, nos processos de elaboração, de avaliação e de acompanhamento dos projetos de curso e propostas político-pedagógicas; e incentivar e oportunizar espaços para que os estudantes sejam ouvidos e possam apresentar propostas. É, ainda, essencial que haja uma reflexão, por parte dos gestores educacionais, na perspectiva de assumir uma liderança política, pedagógica e organizacional, não se restringindo apenas a uma gestão meramente burocrática (ARAÚJO; SILVA, 2017).

Nesse sentido, é essencial que se perceba a complexidade de se concretizar a prática educacional com vistas a alcançar a efetiva implementação do Ensino Médio Integrado. Por isso, se faz necessário um comprometimento, por parte de todos os envolvidos, para que haja uma transformação da realidade escolar.

Para tanto, buscar-se-á tratar sobre os princípios norteadores para uma gestão escolar na perspectiva da legislação educacional e dos documentos institucionais.

\subsection{Gestão Escolar e Conselho de Classe}

A educação, descrita por Lück (2009), é um complexo processo sistematizado, organizado e intencional. Para que seja de qualidade, demanda não só um grande quadro funcional, como também a participação de pais e de responsáveis, da comunidade escolar e de organizações diversas. Para que este processo de formação humana seja desenvolvido, é necessário que haja diretrizes norteadoras e princípios fundamentais.

A Lei de Diretrizes e Bases - LDB em seu art. $2^{\circ}$, dispõe a educação como: "[...] dever da família e do Estado, inspirada nos princípios de liberdade e nos ideais de solidariedade humana, tem por finalidade o pleno desenvolvimento do educando, seu preparo para o exercício da cidadania e sua qualificação para o trabalho" (BRASIL, 1996).

Lück (2009, p.20) ainda aponta que a educação desenvolvida pela escola se trata:

[...] de um processo sociopedagógico voltado para a mobilização do talento humano e o seu desenvolvimento, mediante a aquisição de conhecimentos, habilidades e atitudes necessários para o exercício consciente, comprometido e pleno da cidadania, englobando a participação no mundo do trabalho e o uso dos bens culturais disponíveis.

Conforme Libâneo et al. (2010), o principal objetivo da escola está no ensino e na aprendizagem do estudante, mediados pelo professor. Para se atingir um bom resultado e os objetivos esperados, a organização escolar deverá estar alinhada ao processo como um todo para, assim, fornecer meios que possibilitem essa mediação.

Uma escola bem organizada e gerida é aquela que cria e assegura condições organizacionais, operacionais e pedagógicas-didáticas que permitam o bom desempenho dos professores em sala de aula, de modo que todos os alunos sejam bem-sucedidos em suas aprendizagens (LIBÂNEO et al., 2010, p.300).

Isto posto, percebe-se que muitos são os desafios para se alcançar uma boa qualidade no ensino escolar. Partindo do pressuposto de que a organização e a gestão escolar são meios que direcionam para a promoção dos resultados no ensino e aprendizagem, compreende-se que a gestão pedagógica contribuirá, de forma direta, na eficiência do processo educacional.

A gestão escolar, compreendida no Projeto Pedagógico Institucional - PPI do IFMT, propõe um olhar para o cenário mundial de transformações culturais, econômicas e geográficas ocorridas nas últimas décadas. As mudanças e a reorganização dos espaços escolares deverão estar alinhadas às transformações.

A gestão democrática que permeia o contexto atual, descrita no PPI do IFMT, versa tanto sobre os processos administrativos como sobre os pedagógicos, visando sempre 
os interesses coletivos, sendo ambos os processos, portanto, orientados por uma perspectiva de fazeres educacionais, que contribuam para novas concepções alinhadas às transformações da sociedade (IFMT, 2019).

Notadamente, a gestão pedagógica tem um papel fundamental na escola. Lück (2009) aponta a gestão pedagógica como a mais importante das dimensões da gestão escolar. Está diretamente envolvida nos processos direcionados à promoção do ensino e aprendizagem. "[...] Trata-se, portanto, da dimensão de ponta, subsidiada por todas as demais, que atuam como apoiadoras e sustentadoras dessa [...]" (Lück, 2009, p. 94).

Partindo desse entendimento, pode-se identificar várias ações e estratégias que contribuem para o bom desenvolvimento do ensino e aprendizagem, tanto para auxiliar o corpo docente quanto o corpo discente. Pensando em uma ação coletiva, no âmbito escolar, identifica-se o Conselho de Classe como uma instância colegiada, com possibilidades de avaliar o trabalho escolar e de diagnosticar questões tanto do aprendizado do discente quanto da prática pedagógica.

Partindo do exposto, buscar-se-á, a seguir, compreender as concepções e as perspectivas para o Conselho de Classe escolar.

\subsubsection{Conselho de Classe - concepções e perspectivas}

O Conselho de Classe surgiu na França, em meados de 1945, com o objetivo de organizar o sistema escolar para o acompanhamento contínuo do estudante. Originouse na reorganização do ensino francês, em um momento direcionado apenas ao encaminhamento de estudantes, a partir da observação de suas aptidões, para as modalidades de ensino que eram ofertadas na época (OLIVEIRA, 2011).

No Brasil, a experiência teve início em 1958, trazida por alguns educadores brasileiros, que foram estagiários na França. A experiência foi possível por já estar em desenvolvimento o ideário da escolanovista, que procurava contrapor a escola tradicional e buscar a valorização do trabalho coletivo (ROCHA, 1984).

Efetivamente, foi instituído no ano de 1971, com a Lei ${ }^{\circ}$ 5692/71 - Lei de Diretrizes e Bases da Educação. Com essa lei teve início uma relativa abertura para os estabelecimentos de ensino criarem seus próprios regimentos, porém não se concretizou puramente em consequência de não haver definições muito claras para tanto. Como o momento político era pautado por atos autoritários não foi possível, na época, construir ações coletivas e democráticas (OLIVEIRA, 2011).

Contudo, foi a partir da LDB de 1971, que se iniciaram as discussões sobre os Conselhos de Classe no âmbito escolar, impulsionadas especificamente pelo artigo $2^{\circ}$ parágrafo único.

[...] a organização administrativa, didática e disciplinar de cada estabelecimento de ensino será regulada no respectivo regimento, a ser aprovado pelo órgão próprio do sistema, com observância de normas fixadas pelo respectivo Conselho de Educação (BRASIL, 1971).
Depois de pouco mais de duas décadas, a nova LDB de $n^{\circ}$ 9394/96, em seu artigo 14, já dispôs em seu texto, os princípios norteadores para uma gestão democrática:

Os sistemas de ensino definirão as formas de gestão democrática do ensino público na educação básica, de acordo com as peculiaridades e conforme os seguintes princípios: I - Participação dos profissionais da educação na elaboração do projeto pedagógico da escola; II - Participação das comunidades escolar e local em conselhos escolares ou equivalentes (BRASIL, 1996).

A partir desse ato, a gestão escolar assumiu um papel em uma nova perspectiva, com um viés mais democrático, possibilitando assim a participação da comunidade escolar em órgãos escolares.

A LDB/96 traz missões importantes para os Municípios, Estados e a União, no que diz respeito a Organização da Educação Nacional, no sentido da construção de seus Planos de Educação, e compromete os estabelecimentos de ensino no processo da construção de suas Propostas Pedagógicas de forma colaborativa.

Nesta perspectiva e em acordo com a LDB/96, o IFMT contempla sua proposta pedagógica no Projeto Pedagógico Institucional - PPI. Este se constitui em um instrumento orientativo e de mediação do trabalho pedagógico para o Instituto. Contempla dois pilares essenciais, conforme a Constituição Federal de 1988, em seus artigos 206 e 214: “[...] a gestão democrática, como um princípio, e o planejamento, como uma necessidade para a superação das defasagens educacionais existentes no país" (IFMT, 2019, p.38).

Outro documento de grande importância para a instituição é a Organização Didática - OD do IFMT, a qual rege os procedimentos didático-pedagógicos e administrativos dos campi e está "[...] em consonância com a Lei de Diretrizes e Bases da Educação Nacional - LDB - Lei n ${ }^{\circ} 9.394$ de 20/12/1996, suas regulamentações, pareceres; as Diretrizes Curriculares Nacionais; Plano de Desenvolvimento Institucional - PDI e o Regimento Geral do IFMT" (IFMT, 2014, p.10).

No IFMT, o Conselho de Classe está disposto na Organização Didática, em seu capítulo III, como sendo um espaço de avaliação constante do desempenho dos estudantes no processo de ensino e aprendizagem. É considerado como um espaço com objetivos de diagnóstico, análise e encaminhamentos pedagógicos, com vistas a superar problemas observados (IFMT, 2014).

Contudo, para que possa efetivamente haver um Conselho de Classe com perspectivas novas, os membros deste conselho devem se apoderar " $[. .$.$] conscientemente, dele, colocando-o$ a serviço de seus propósitos, articulando-o com um Projeto Político Pedagógico comum" (DALBEN, 2004, p.59).

Isto posto, identifica-se o Conselho de Classe como um órgão colegiado articulado com as diretrizes educacionais, normas, projetos políticos pedagógicos institucionais e bem conduzido por uma gestão pedagógica comprometida com o 
processo de ensino e aprendizagem. Com tal perfil, o Conselho de Classe se torna um aliado para a qualidade do ensino.

Esse espaço pode ser tratado como uma oportunidade para realizar a avaliação diagnóstica de todo o processo pedagógico-educativo. Assim, esse seria o momento de avaliar se a prática está em consonância com a proposta pedagógica da escola. "O Conselho de Classe, nesse contexto está vinculado ao currículo, ao Projeto Político Pedagógico e colabora para a avaliação e a recondução do processo de ensino-aprendizagem" (PIZOLI, 2009, p. 6916).

Notadamente, para que ocorra o devido acompanhamento e melhoria do processo educacional, o Conselho de Classe deve ter um papel importante perante a avaliação educacional, no sentido de serem complementares entre si. Portanto, será tratado a seguir a prática do Conselho de Classe e sua dimensão avaliativa.

\subsubsection{Conselho de Classe - um espaço de avaliação}

Ao compreender o Conselho de Classe como uma etapa dinamizadora do trabalho educativo, Cruz (2015) pressupõe que as etapas de todo o processo estejam inter-relacionadas, como forma de consolidar ações concretas, com vistas a interferir na prática educativa. O autor relaciona o Conselho de Classe como um espaço de avaliação, tanto do trabalho individual como também de todos os envolvidos no processo. Nesse sentido, o Conselho de Classe ajudará a equipe a se conhecer melhor, possibilitando um momento de crescimento pessoal e coletivo.

Lück (2012) considera a avaliação como uma forma de possibilitar uma melhoria contínua do processo educacional. Para isso, o trabalho educacional deve estar acompanhado de processos de avaliação, que envolvam ações bem definidas e bem orientadas. Muitas são as formas de avaliação na escola com o objetivo de medir o desempenho e o rendimento dos estudantes. Essas avaliações podem ser obtidas por mecanismos externos, como é o caso por exemplo do ENEM (Exame Nacional do Ensino Médio) ou realizada pela própria escola. Essa última caracterizada como autoavaliação.

A avaliação institucional realizada pela própria escola, propõe uma visão mais detalhada, pois serão considerados os aspectos de observação, de análise e de interpretação do próprio meio (LÜCK, 2012).

Compreendendo a avaliação como parte integrante no processo educacional, Guerra (2011) observa que para se avaliar é imprescindível saber quais respostas se deseja conseguir e ter em mente como será possível traçar alternativas em busca de transformações. Nesse sentido, a avaliação envolve uma série de questões internas vivenciadas pelos atores envolvidos. Assim, faz-se necessário que todos os educadores estejam em constante "[...] avaliação reflexiva para saber, com nitidez, como funciona o processo de ensinoaprendizagem, uma vez que quem ensina precisa continuar aprendendo com e sobre a prática" (GUERRA, 2011, p.37).
Lück (2012) considera que a avaliação Institucional está a serviço da gestão escolar e envolve três funções básicas de organização: o planejamento, o monitoramento e a avaliação. A autora complementa que sendo a educação escolar um processo intencional, sistemático e orientado para promoção de resultados, se faz necessário que o planejamento de suas práticas seja muito bem delineado.

Contudo, observa-se que a prática educativa é bastante complexa, pois envolve muito trabalho e dedicação. Para que se tenha um bom desempenho, Lück (2012) evidencia que a avaliação deve estar a serviço da gestão educacional, por constituir um trabalho que envolve orientação, organização e mobilização. A avaliação institucional, como um instrumento de gestão, se torna parte do planejamento educacional, contribuindo dessa forma, para o monitoramento das práticas educativas na busca de melhorias.

Ao considerar a avaliação educacional parte constituinte do processo educacional, observa-se que há uma inter-relação com o Conselho de Classe. Nesse sentido, Cruz (2015, p.11) compreende o Conselho de Classe como:

[...] um espaço de avaliação do trabalho individual e coletivo da equipe de professores e da coordenação pedagógica sobre o próprio trabalho, o conselho de classe é a busca conjunta de alternativas de ações concretas/atitudes que levam à consecução dos objetivos propostos no Projeto Político Pedagógico.

Para Libâneo (2018), o Conselho de Classe é uma instância que permite um acompanhamento do estudante, tendo como foco a análise da turma e do desempenho do professor. Em alguns casos, pode se tornar um meio para a formulação de propostas de integração e iniciativas de apoio. Conforme o autor, se sua competência for efetivamente praticada, este órgão se tornará muito interessante sob o ponto de vista pedagógico-didático.

Percebe-se que não é uma tarefa fácil contemplar essa busca de ações conjuntas, porém para que se efetive a transformação do processo de ensino e de aprendizagem na escola é preciso que haja um engajamento coletivo, por parte de todos os envolvidos e, claro, com ações bem orientadas, organizadas administrativamente e contínuas. Sabe-se que as transformações não ocorrem de forma imediata, portanto há a necessidade de continuidade e constante aprimoramento.

\subsection{O Conselho de Classe no IFMT - Campus Cuiabá Cel. Octayde Jorge da Silva}

A análise dos documentos institucionais teve como foco a investigação nas legislações e atos normativos alusivos ao Conselho de Classe no IFMT, emitidos pela Reitoria e pelo campus em estudo.

Nesse contexto, inicia-se a análise documental partindo da Resolução do Conselho Superior do IFMT, no 104, de 15 de dezembro de 2014, que dispõe e aprova a Organização Didática do IFMT, vigente até o presente momento. Primeiramente, constatou-se que esse documento institucional, em seu art. 
$1^{\mathrm{o}}$, dispõe sobre os procedimentos didáticos-pedagógicos e administrativos para o IFMT e estão em consonância com o que estabelece a LDB/96 e o Plano de Desenvolvimento Institucional do IFMT.

Isto posto, procurou-se identificar, inicialmente, algumas diretrizes indutoras para o desenvolvimento da prática educacional na escola pública. Para tanto, prosseguiu-se para a análise do art. 14 e 15 da LDB/96, disposto a seguir:

Art. 14 Os sistemas de Ensino definirão as normas da gestão democrática do ensino público na educação básica, de acordo com as suas peculiaridades e conforme os seguintes princípios: I- Participação dos profissionais da educação na elaboração do projeto pedagógico da escola; II- Participação das comunidades escolar e local em conselhos escolares ou equivalentes.

Art. 15 Os sistemas de Ensino assegurarão às unidades escolares públicas de educação básica que os integram progressivos graus de autonomia pedagógica e administrativa e da gestão financeira, observadas as normas de direito financeiro público.

Tal diretriz oferece o princípio da autonomia pedagógica e administrativa, mas não de forma definida. Estabelece um encaminhamento para os sistemas de ensino definirem suas normas em conformidade com alguns princípios postos, como o da participação da comunidade escolar em conselhos escolares.

Em conformidade com a LDB, o PDI/IFMT traduz a forma pela qual a democratização no IFMT pode ser percebida, sendo identificada como a "[...]democratização dos processos pedagógicos, com respeito à construção coletiva e emancipadora; progressiva adesão ao trabalho interdisciplinar; reavaliação curricular; avaliação processual" (IFMT, 2019, p.80).

Diante do exposto, observa-se que as diretrizes norteadoras apontam para uma forma de gestão escolar democrática, devendo ser desenvolvida com a participação dos diferentes segmentos pertencentes a comunidade escolar. Contudo, é imprescindível que os próprios sistemas de ensino propiciem formas para que se possa conquistar essas ações coletivas e emancipatórias.

Note-se que o fazer pedagógico deve ser discutido, analisado e avaliado, constantemente, em espaços constituídos para isso. Portanto, é imprescindível que todos os envolvidos compreendam a: "[...] dimensão política de sua ação administrativa, respaldada na ação participativa, rompendo com a rotina alienada, o mando impessoal e racionalizado da burocracia" (IFMT, 2019, p.81).

Em prosseguimento à análise, procurou-se estabelecer um contato direto com o documento institucional que possibilitasse uma dimensão clara do que está posto sobre o Conselho de Classe, no âmbito do IFMT. Assim, encontrase sua definição, conforme art. 44 da Organização Didática/ IFMT:

O Conselho de Classe é o espaço de avaliação constante do desempenho dos discentes no desenvolvimento do processo ensino-aprendizagem com o objetivo de diagnosticar problemas, analisar resultados e apontar encaminhamentos pedagógicos necessários para superar problemas detectados, devendo prevalecer os aspectos qualitativos sobre os quantitativos. Parágrafo único. O Conselho de Classe tem função de acompanhamento da situação acadêmica do discente, não cabendo a ele a decisão sobre aprovação (IFMT, 2014).

Percebe-se, então, pelo que está posto na Organização Didática, que o Conselho de Classe tem uma função importante no tocante ao acompanhamento do processo ensino e aprendizagem. Nesse sentido, torna-se uma instância de acompanhamento pedagógico do estudante em todo o seu percurso escolar, devendo sempre prevalecer os aspectos qualitativos sobre os quantitativos. Não cabendo a esse espaço decisões sobre aprovação ou reprovação, mas sim, uma contínua busca de soluções para os problemas detectados durante o processo ensino e aprendizagem.

Foram identificados mais quatro artigos na Organização Didática que estabelecem diretrizes para o Conselho de Classe, dispostos a seguir:

Art. $44 \mathrm{O}$ conselho de classe deverá ser composto por todos os docentes da turma, coordenador de curso, diretor de ensino/ chefe de departamento, pedagogo e servidores que atuam diretamente com atendimento pedagógico.

Parágrafo único. Os discentes representantes de turma poderão participar dos Conselhos de Classe sempre que houver questões relacionadas a fatos que envolvam as turmas representadas por eles.

Art. 45 Todos os membros do Conselho de Classe possuem direito a voto, exceto o Coordenador do Curso. Parágrafo único. Caberá ao Coordenador de Curso o voto de desempate, exceto quando se tratar de situações em que esteja envolvido na condição de docente.

Art. 46 Compete ao Coordenador de Curso: I - presidir as atividades do Conselho; II - definir horário das reuniões; III indicar membro do Conselho para secretariar as reuniões; e IV - coordenar as ações visando sanar os problemas pedagógicos constatados. Parágrafo único. Caberá ao coordenador pedagógico presidir as reuniões, quando o coordenador de curso estiver envolvido na condição de docente, cuja situação requeira reflexão e decisão.

Art. 47 O Conselho de Classe deverá se reunir no mínimo uma vez a cada bimestre e realizar o registro sistemático de todas as ações e decisões tomadas pelo mesmo em ata (IFMT, 2014).

Partindo do exposto na Organização Didática, quanto ao delineamento da organização e funcionamento do Conselho de Classe, no âmbito do IFMT, observa-se que sua composição busca atender a participação de todos os profissionais, que fazem parte do processo educacional. Note-se que a participação do discente está prevista, contudo, não estabelece uma obrigatoriedade.

Ainda, em continuidade à análise da Organização Didática, quanto ao formato de aplicação do Conselho de Classe, no âmbito do IFMT, o coordenador de curso assume a função primordial, em todo o desenvolvimento do processo, cabendo a ele presidir a aplicação, estabelecer os horários das reuniões e coordenar o plano de ação, que será estabelecido durante a reunião, com a finalidade de resolver questões que foram identificadas. $\mathrm{O}$ coordenador também poderá indicar algum 
membro para auxiliar e secretariar na hora da reunião.

Está definido, no art. 46 da Organização Didática, que o coordenador pedagógico deverá assumir a presidência da reunião, quando o coordenador de curso for docente da turma em questão, neste caso, quando esteja envolvida alguma tomada de decisão que o requeira. Quanto à periodicidade, as reuniões devem ocorrer no mínimo uma vez a cada bimestre e serem devidamente registradas em ata, conforme identificado no art. 47. Constatou-se, também, que o regulamento didático, em seu Art. 27, contempla a obrigatoriedade de estar identificado no calendário acadêmico de cada campus as datas dos Conselhos de Classe de cada período letivo.

Nesse sentido, observa-se que há uma preocupação da Instituição para que o planejamento do Conselho de Classe seja antecipado e efetivamente organizado, tendo em vista a grande importância desta instância na perspectiva pedagógica. Outrossim, prevê grande mobilização de profissionais da área de ensino como: professores, pedagogos, coordenadores de curso, técnicos em educação, entre outros.

$\mathrm{Na}$ pesquisa documental foram encontrados também diversos registros da prática do Conselho de Classe, identificada por meio de algumas ações como: definições das datas no calendário acadêmico; atas de reuniões de conselho de classe; convocação aos membros; respostas de discentes e docentes às pesquisas de diagnóstico; e encaminhamento de estudantes para acompanhamento psicológico e/ou pedagógico.

Todavia, não foi encontrado nenhum documento específico para o Conselho de Classe, com orientações claras para a execução, para o uso dos instrumentos de diagnóstico e acompanhamento, nem para a autoavaliação do processo. Nesse sentido, entende-se que o desenvolvimento prático desta instância pode acabar sofrendo muitas variações dentro da mesma unidade escolar, em função de interpretações diversas, por parte da coordenação do curso ou da gestão institucional. Tal preocupação toma maior vulto quando se trata de um campus com muitos cursos, vinculados às diferentes áreas do conhecimento, ficando assim susceptíveis às diferentes formas de condução.

Isso posto, entende-se que a ausência de direcionamento, no sentido da sistematização dessa prática, pode ocasionar uma desconexão entre os vários Conselhos de Classe dentro de uma mesma unidade de ensino. Consequentemente, pode haver um prejuízo em alcançar os objetivos esperados para este espaço, que vem a ser o acompanhamento e as ações de melhoria para o ensino e aprendizagem.

\section{Conclusão}

Este trabalho teve como objetivo descrever e trazer reflexões sobre os elementos constitutivos para a organização e o funcionamento dos Conselhos de Classe. Motivouse pela expectativa de diagnosticar, a partir da base legal e dos documentos institucionais vigentes, a atual forma de organização e de funcionamento do Conselho de Classe no
IFMT.

Nesse contexto se salienta que, ao buscar referências na literatura técnica sobre o tema Conselho de Classe, observouse que este não tem sido objeto de muitas pesquisas e sua literatura específica é bem limitada.

Foi constatado que a LDB/96 estabelece que o Conselho de Classe deve ser instituído, nas escolas de forma participativa e colegiada e os documentos institucionais (Projeto Pedagógico Institucional e Organização Didática), que apresentam direcionamentos de como o Conselho de Classe deve acontecer no IFMT. Contudo, não foram encontrados documentos ou instrumentos com orientações práticas para a sua organização e funcionamento.

Assim, considera-se pertinente que sejam construídos documentos com orientações objetivas, bem como instrumentos para coleta de dados, de diagnóstico, de análise e de acompanhamento das ações propostas durante a reunião do Conselho. A sistematização e a institucionalização de tais procedimentos podem proporcionar uma melhor gestão do processo, reduzir o risco de distorção na interpretação de conceitos e na condução dos trabalhos, além da possibilidade de oportunizar, em seu bojo, uma ação mais reflexiva e avaliativa dessa importante instância colegiada.

\section{Referências}

ARAÚJO, A.C.; SILVA, C.N.N. Instituto Federal de Brasília. Ensino Médio Integrado no Brasil: fundamentos, práticas e desafios. Brasília: IFB, 2017.

ARAUJO, R.M.L; FRIGOTTO, G. Práticas pedagógicas e ensino integrado. Rev. Educ. Questão, v.52, n.38, p.61-80, 2015.

BRASIL. Lei 11.892/2008, de 29 de dezembro de 2008. Institui a Rede Federal de Educação Profissional, Científica e Tecnológica, cria os Institutos Federais de Educação, Ciência e Tecnologia, e dá outras providências. Sessão 1 , art. $7^{\circ}$; art. $12^{\circ}$. Presidência da República, 2008.

BRASIL. Ministério da Educação. Lei no 9.394, de 20 de dezembro de 1996. Estabelece as diretrizes e bases da educação nacional. Diário Oficial da União, Brasília: MEC, 1996.

BRASIL. Lei no. 5692/71, de 20 de dezembro de 1971. Fixa Diretriz e Bases para Brasília, DF, 1971. Disponível em: <https:// www2.camara.leg.br/legin/fed/lei/1970-1979/lei-5768-20dezembro-1971-357812-publicacaooriginal-1-pl.html >. Acesso em: 10 maio 2020.

COSTA, A.M.R. Integração do ensino médio e técnico: percepções de alunos do Instituto Federal de Educação, Ciência e Tecnologia do Pará - IFPA/Campus Castanhal. Belém: Universidade Federal do Pará, 2012.

CRUZ, C. H. C. Conselho de Classe: espaço de diagnóstico da prática educativa escolar. São Paulo: Loyola, 2015.

DALBEN, Â.I.L.F. Conselhos de Classe e Avaliação. Perspectivas na gestão pedagógica da escola. Campinas: Papirus, 2004.

DALBEN, Â.I.L.F. Trabalho escolar e Conselho de Classe. Campinas: Papirus, 1992.

DOURADO, L. F. Gestão em educação escolar. Profuncionário Módulo pedagógico. Brasília: MEC, 2012.

GUERRA, M.G.G. Formação de professores e coordenadores: o 
Conselho de Classe na perspectiva crítica. São Paulo: SBS, 2011.

IFMT - Instituto Federal de Educação, Ciência e Tecnologia de Mato Grosso. Organização Didática do Instituto Federal de Educação, Ciência e Tecnologia de Mato Grosso. Cuiabá: IFMT, 2014.

IFMT - Instituto Federal de Educação, Ciência e Tecnologia de Mato Grosso. Plano de Desenvolvimento Institucional. Cuiabá,: IFMT, 2019.

LIBÂNEO, J.C.; OLIVEIRA, J.F.; TOSCHI, M.S. Educação escolar: políticas, estrutura e organização. São Paulo: Cortez, 2010.

LIBÂNEO. J.C. Organização e gestão escolar: teoria e prática. São Paulo: Herccus, 2018.

LÜCK, H. Dimensões da gestão escolar e suas competências. Curitiba: Positiva, 2009.

LÜCK, H. Perspectivas da avaliação institucional da escola. Petrópolis: Vozes, 2012.
MARCONI, M.A.; LAKATOS, E.M. Fundamentos de metodologia cientifica. São Paulo: Atlas, 2017.

MINAYO, M.C.S.O. Pesquisa Social. In: MINAYO, M.C.S.; DESLANDES, S.F.; GOMES, R. Pesquisa social: teoria, método e criatividade. Petrópolis, RJ: Vozes, 2002.

OLIVEIRA, M. O papel do Conselho de Classe na Escola Pública Atual. In: PARANÁ. Secretaria de Estado da Educação. Superintendência de Educação. O professor PDE e os desafios da escola pública paranaense, 2008. Curitiba: SEED/PR, 2011.

PIZOLI, R.C. A função do Conselho de Classe na Organização do Trabalho Pedagógico Escolar. In: CONGRESSO NACIONAL DE EDUCAÇÃO. EDUCERE. PUCPR, 2009.

RAMOS, M.N. Concepções do Ensino Médio Integrado. Natal: Secretaria de Educação do Estado do Rio Grande do Norte, 2007.

ROCHA, A.D.C. Conselho de classe: burocratização ou participação. Rio de Janeiro: F. Alves, 1984. 